\title{
ESTÁGIO DE DOCÊNCIA, PRÁTICA JURÍDICA E DISTRIBUIÇÃO DA JUSTIÇA
}

\author{
Denise Pires Fincato \\ TEACHING INTERNSHIP, LEGAL PRACTICE \\ AND DISTRIBUTION OF JUSTICE
}

\section{RESUMO}

O ENSINO JURÍDICO EM SEU NASCEDOURO: CURSOS DE PÓSgraduação em Direito, berçários docentes. PARTE-SE do PRESSUPOSTO DE QUE NAS DISCIPLINAS DE PRÁTICA JURIDICA (PRINCIPALMENTE AS DE CAMPO: ESTÁGIOS CURRICULARES OBRIGATÓRIOS) O DOCENTE DEVE TER MAIOR IDENTIDADE COM A REALIDADE SOCIAL, JÁ QUE SEU OBJETO DE ENSINO É O SUBSTRATO SOCIAL, COMPLEXO, EIVADO DE PROBLEMAS E CARÊNCIAS. NESSE SENTIDO, VERIFICAM-SE FRAGILIDADES NOS ESTÁGIOS DE DOCÊNCIA, NORMALMENTE OCUPADOS POR DISCIPLINAS PERTENCENTES AOS DEMAIS EIXOS FORMATIVOS. UTILIZAM-SE NA PESQUISA OS MÉTODOS INDUTIVO, TIPOLÓGICO E DE INTERPRETAÇÃO SOCIOLÓGICA E TÉCNICAS DE PESQUISA BIBLIOGRÁFICO-DOCUMENTAIS. DAS REFLEXÕES, A CERTEZA DE QUE OS PROGRAMAS PODEM FORMAR DOIS TIPOS DE DOCENTES: ACOMODADOS OU TRANSFORMADORES, TUDO DEPENDENDO DA EStRatégIa PEDAgógICA (METOdOLOGIA DE ENSINO) QUE EMPREGAREM. A COMPREENSÃO E POSTERIOR DISTRIBUICÃO DA JUSTICCA TÊM SEU LUGAR DE ENSAIO NA REALIDADE SÓCIOJURÍDICA, FATO PELO QUAL NECESSÁRIA É A ATENÇÃO DOS PROGRAMAS DE PÓS-GRADUAÇÃO AO ESTAGIO DE DOCÊNCIA EM DISCIPLINAS DE PRÁTICA JURÍDICA.

\section{PALAVRAS-CHAVE}

ENSINO; PRÁTICA; ESTÁGIO DE DOCÊNCIA; PÓS-GRADUACC̄Ã; JUSTICA.

\section{ABSTRACT}

TEACHING LAW IN ITS OUTSET: POSTGRADUATE STUDIES IN LAW. TEACHER'S NURSERY. THE ARTICLE STARTS FROM THE ASSUMPTION THAT REGARDING THE DISCIPLINES OF LEGAL PRACTICE (MAINLY THE FIELD ONES, MANDATORY INTERNSHIPS) THE TEACHER SHOULD HAVE A GREATER IDENTITY WITH SOCIAL REALITY, SINCE THE OBJECT OF EDUCATION IS THE SOCIAL SUBSTRATUM, WICH IS COMPLEX AND RIDDLED WITH PROBLEMS NEEDS. IN THIS SENSE, THERE ARE WEAKNESSES IN TEACHING INTERNSHIPS, NORMALLY OCCUPIED WITH SUBJECTS THAT PERTAIN TO OTHER TRAINING ROUTES. IN RESEARCH WE USED INDUCTIVE, TYPOLOGICAL AND SOCIOLOGICAL INTERPRETATION METHODS AND TECHNICAL RESEARCH LITERATUREDOCUMENTARY. FROM REFLECTIONS, COMES THE CERTAINTY THAT THE PROGRAMS CAN FORM TWO KINDS OF TEACHERS: THE STAYING OR THE PROCESSORS, DEPENDING ON THE PEDAGOGICAL STRATEGY (TEACHING METHODOLOGY) THAT ARE EMPLOYED. THE UNDERSTANDING AND THE DISTRIBUTION OF JUSTICE HAS ITS TEST PLACE IN THE SOCIO-LEGAL REALITY AND WE THEREFORE NEED THE POST-GRADUATE PROGRAMS ATTENTION TO INTERNSHIP TEACHING IN THE DISCIPLINES OF LEGAL PRACTICE.

\section{KEYWORDS}

TEACHING; TRAINING; PROBATION INTERNSHIP; POSTGRADUATE STUDIES LAW; JUSTICE.

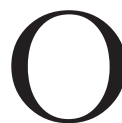
s cursos de pós-graduação no Brasil são regrados pelo Ministério da Educação em colaboração com a Coordenação de Aperfeiçoamento de Pessoal de Ensino Superior (CAPES). Em seus regramentos, há a obrigatoriedade, principalmente por parte do aluno bolsista, de frequentar e ser aprovado no chamado estágio de docência. 
No estágio de docência, os mestrandos e doutorandos ficam face a face com os afazeres diários do magistério jurídico de graduação: o planejamento das aulas; a ideação das atividades; a elaboração, aplicação, correção e entrega das avaliações; as classes em sua dinâmica; a administração dos conflitos etc., tudo sempre assistido e supervisionado pelo professor titular da disciplina, quem emitirá parecer em relatório de aproveitamento. Nesse sentido, o artigo 22 da Portaria n 34/2006 da CAPES:

\section{Estágio de Docência}

Art. 22. O estágio de docência é parte integrante na formação do pós-graduando, objetivando a preparação para a docência, a qualificação do ensino de graduação, e será obrigatório para todos os bolsistas do PROEX, obedecendo aos seguintes critérios:

I - para o programa que possuir os dois níveis, mestrado e doutorado, a obrigatoriedade estará restrita ao Doutorado;

II - a duração mínima do estágio de Docência será de um semestre;

III - o docente de ensino superior que comprovar atividades docentes acatadas pela CG/PROEX, ficará dispensado do estágio de docência;

IV - as atividades do estágio de Docência deverão ser compatíveis com a área de pesquisa no programa de pós-graduação realizada pelo pós-graduando;

$\S 1^{\circ}$ As instituições que não oferecerem curso de graduação deverão associar-se a outras instituições de ensino superior para atender as exigências do estágio de Docência;

$\S 2^{\circ} \mathrm{O}$ estágio de Docência com carga superior a sessenta horas poderá ser remunerado a critério da IES, vedada a utilização de recursos repassados pela CAPES; $\S 3^{\circ}$ Compete à CG/PROEX, registrar e avaliar o estágio de Docência para fins de crédito do pós-graduando, bem como a definição quanto a supervisão e o acompanhamento do estágio;

$\S 4^{\circ}$ Havendo específica articulação entre os sistemas de ensino pactuada pelas autoridades competentes, e observadas as demais condições estabelecidas neste artigo, admitir-se-á a realização do estágio de Docência na rede pública do ensino médio.

O objetivo do estágio de docência, então, é contribuir na preparação do docente que atuará nos cursos de graduação. O estágio deve trazer, enquanto ato educativo escolar supervisionado que é, a conexão entre teoria e prática, o desenvolvimento ou aperfeiçoamento das habilidades necessárias ao exercício do mister para o qual se estuda.

Vê-se, no meio acadêmico, que os estágios jurídicos de docência têm se ocupado muito mais com as disciplinas dos chamados eixos de formação fundamental e profissional dos cursos de direito, deixando a latere as disciplinas do chamado eixo 
prático. ${ }^{1}$ Não há, em verdade, “estágio de docência” em disciplinas do Núcleo de Prática Jurídica, salvo exceções (desconhecidas, diga-se de passagem).

Será em virtude da crença de que mestrado ou doutorado (em direito) não possuem (ou não devem possuir) cunho prático? Ou será que as disciplinas práticas são "menos nobres" que as disciplinas de formação fundamental e profissional? O fato é que muitos mestres recém-saídos da academia têm dificuldades em atribuir tal qualidade (prática) às suas lições, esquecendo-se que mesmo as disciplinas fundamentais ou profissionais têm de ser práticas, isto é, significativas, marcantes, vivenciais. E isso traz consigo um sério prejuízo à própria sociedade, já que os profissionais formados nesses cursos jurídicos provavelmente conhecerão um direito folhetinesco, utópico e extremamente teórico e, assim, pouco ou nenhum contato terão com a realidade com a qual irão trabalhar ou com uma realidade à qual aplicar o "direito posto". Também não reconhecerão as hipóteses para as quais não há, ainda, "direito posto" e cujos conflitos, apesar disso, clamam por solução.

Então, para prosseguir no presente estudo, é necessário buscar o significado da expressão prática, de modo a vinculá-la ao contexto dos cursos de direito e da formação "jurídica” em si. Assim, é pertinente a indagação: o que é prática? E como se adquire a prática, em qualquer área?

Defende-se aqui a ideia de que tudo começa pela busca do prazer e pela necessidade de satisfação das curiosidades. Utilizando como paradigma a culinária, poder-se-ia dizer que um iniciante na arte da culinária busca conhecer a textura, o aroma, o sabor e a compatibilidade dos alimentos. Tem prazer em fazê-lo, tem curiosidade quanto aos resultados. Mas, até aí, não passa de alguém com "jeito para a cozinha”, um prático, apenas.

Com a organização do talento em estudos sistematizados, é que se abre, então, a possibilidade de optar por continuar sendo alguém com "jeito para a cozinha” ou um grande chef. Mas, para ser um chef, será necessário mais que prazer e curiosidade (catalisadores dos ditos jeitosos). Para ser um chef, será necessário aliar à prática boa fundamentação teórica, bases científicas. Será preciso estudar os alimentos em sua composição e seus nutrientes, anotar, testar, ler e, sobretudo, pensar. Será preciso ter a certeza de que, além de testar novos ingredientes e suas múltiplas relações, estar-se-á contribuindo para uma melhor alimentação do ser humano e, ainda, de certa forma, para suprimir a fome do rol dos flagelos humanos.

Chama-se atenção para o fato de que a prática jurídica ocorre sempre que se atribui significado ao que se ensina: concretudes, aplicabilidades, viabilidades na área jurídica (ou ao menos quando se permite sua construção). Ou seja, é possível até mesmo fazer práticas filosóficas, se for do interesse do praticante, seja ele o aprendiz ou o professor.

O ensino irrigado de prazer, que transborde do próprio prazer da docência e da atividade jurídica do docente, é um ensino que desperta a curiosidade, e, com isso, 
nada resta no plano único e exclusivo do abstrato, surreal ou inaplicável (e sem importância, no contexto do discente), uma vez que o aprendiz curioso e cheio de desejo em satisfazer-se buscará construir/atribuir significados (mesmo que permeados por suas experiências) aos objetos (conhecimento) que lhe são apresentados.

As diretrizes curriculares dos cursos jurídicos não erram ao apontar a necessidade de existência dos três eixos formativos (formação fundamental, profissional e prática), ${ }^{2}$ de forma concomitante, desde o primeiro nível do curso (semestre ou ano). Destaca-se, então, o direcionamento legal para a necessária conjugação das dimensões prática, fundamental e profissional nos estudos jurídicos desde seus primeiros momentos.

A primeira norma para o então Estágio de Prática Forense e Organização Judiciária foi a Lei 5.842/72, regulamentada pela Resolução 15/73 do Conselho Federal de Educação. Verifica-se que o estágio possuía caráter facultativo, mas, uma vez cursado, conferia-se ao aluno o direito de se inscrever nos quadros de advogados da Ordem dos Advogados do Brasil (OAB) - sem a atual imposição de aprovação no exame da Ordem.

Tal realidade mudou substancialmente em 1994, com a Portaria 1.886 do Ministério de Educação e Cultura que, quanto ao tema estágios, fixou as seguintes diretrizes mínimas, conforme Rodrigues (1995):

a) O estágio deixou de denominar-se prática forense para passar a chamar-se prática jurídica. Essa troca do adjetivo qualificador traz no seu bojo uma enorme ampliação de horizontes. Os estágios sempre estiveram voltados apenas para a prática do foro [prática forense], como se aí residisse todo o direito. O mundo contemporâneo tem caminhado muito em outros sentidos. Hoje as assessorias e consultorias, os substitutivos processuais, como a arbitragem, entre outras realidades, todas jurídicas, demonstram a necessidade de uma formação prática mais ampla.

b) A definição de que o estágio se compõe de atividades práticas, simuladas e reais. No sistema anterior, embora isso estivesse subjacente à expressão estágio supervisionado, na prática as instituições transformaram a prática forense em um espaço limitado à sala de aula, onde se repetiam as aulas de direito processual, apenas em um viés mais preocupado com seus aspectos práticos. Essa possibilidade, frente ao novo texto, fica agora inviabilizada. O estágio deve necessariamente ser composto de atividades práticas.

c) A Portaria também avança ao dividir a prática em real e simulada, qualificandoa. Isso significa que, naquilo em que for possível, a prática deve estar vinculada a situações reais da vida profissional, como nos serviços de assistência jurídica, patrocinados por alguns cursos jurídicos nacionais. Mas ao lado dessa prática real, impõe também como necessária uma prática simulada daquelas situações para as quais não é possível uma vivência prática correta durante o estágio supervisionado. (p. 49) 
Atualmente, o curso jurídico encontra-se regido pela Resolução $\mathrm{n}^{\circ} 9$ do CNE/CSE, de 29 de setembro de 2004, ${ }^{3}$ e em tal documento vislumbram-se diversas referências diretas ou indiretas (mas sempre intrínsecas ou conexas) à prática jurídica, tais como a necessária estruturação do projeto pedagógico de cada curso, onde expressamente conste, dentre outros, o estágio curricular supervisionado (artigo $2^{\circ}$ ).

Como elementos estruturais de tal projeto pedagógico deverão constar $\left(\S 1^{\circ}\right)$ :

[...] IV - formas de realização da interdisciplinaridade; V - modos de integração entre teoria e prática; [...] IX - concepção e composição das atividades de estágio curricular supervisionado, suas diferentes formas e condições de realização, bem como a forma de implantação e a estrutura do Núcleo de Prática Jurídica.

Quanto ao perfil de graduando desejado, o artigo $3^{\circ}$ de referida resolução indica expressamente que o curso deverá assegurar:

[...] sólida formação geral, humanística e axiológica, capacidade de análise, domínio de conceitos e da terminologia jurídica, adequada argumentação, interpretação e valorização dos fenômenos jurídicos e sociais, aliada a uma postura reflexiva e de visão crítica que fomente a capacidade e a aptidão para a aprendizagem autônoma e dinâmica, indispensável ao exercício da Ciência do Direito, da prestação da justiça e do desenvolvimento da cidadania.

Ou seja, é necessário instigar a busca pelas respostas, a superação da memorização displicente e descompromissada. É preciso independentizar o graduando, fomentar o seu pensamento crítico, lógico e, principalmente, autônomo. É preciso fazer que ele reconheça os fenômenos sociais pendentes de respostas jurídicas e, sobretudo, encorajá-lo a ousar responder. A prática realiza o aprendizado teórico, fixa-o como experiência de vida, e esta, como andar de bicicleta ou cozinhar, não se esquece em sua essência, mesmo passados muitos anos.

Parece óbvio, por conseguinte, que a realidade dos chamados estágios de docência, próprios dos cursos de pós-graduação strictu sensu, deva seguir uma linha idêntica de atuação e estruturação. Formar chefs que formarão novos chefs, eis seu desafio.

Para que o desiderato seja alcançado, uma tradição no ensino jurídico tem de ser revista: sua metodologia, a qual, salvo raras exceções, segue um padrão que não se adapta ao contexto atual.

No Brasil, os primeiros cursos jurídicos surgiram em 1827, seguindo o modelo lusitano (chamado Coimbrão, no meio acadêmico), não só em sua estrutura curricular, como também na proposta pedagógica (a última de abrangência muito além da questão didática, chegando à concepção do curso e à definição do perfil do egresso). Desde o dia 11 de agosto de 1827, com a "Lei que Cria os Cursos de Ciências Jurídicas 
e Sociais em São Paulo e Olinda”, vê-se uma preocupação com a prática jurídica (teoria e prática do processo adotadas pelas leis do império), mesmo que alocada explicitamente apenas no último ano do curso. ${ }^{4}$

Entretanto, atestam diversos estudiosos da matéria que a finalidade dos cursos jurídicos foi desvirtuada desde o seu nascedouro (ADORNO, 1998, p. 81). Métodos e conteúdos se deixaram render à necessidade premente de formação dos quadros da recém-nascida burocracia brasileira.

A Academia de Direito de São Paulo - assim como a de Olinda - teve suas raízes atadas à necessidade de independência político-administrativa brasileira. Com a emergência do Estado Nacional, suscitou-se o delicado problema de autonomia cultural da sociedade brasileira, além da imperiosa e urgente formação dos quadros funcionais para o aparelho estatal.

Segundo Adorno (1998), os cursos jurídicos foram durante muito tempo os depositários dos desejos de liberdade, democracia, consciência e cidadania da sociedade, que vislumbrava em seus acadêmicos os estandartes de um novo tempo. A frustração em decorrência da não realização dessas expectativas é retratada em diversos textos, estudos e documentos. Na realidade, o somatório de sucessivos governos autoritários, a explosão quantitativa dos cursos jurídicos e o desejo de rapidamente aparelhar o Estado com funcionários de "nível superior" (mas facilmente manipuláveis, porque desprovidos de raciocínio lógico e jurídico) geraram o insucesso comentado e o descrédito dos estudantes e profissionais do direito, extensivo ao Poder Judiciário e ao próprio direito (a este, porque sedizente solucionador das controvérsias decorrentes do convívio humano, e àquele, porque de exercício exclusivo de bacharéis em direito).

Observou-se (e ainda se observa) um crescente distanciamento dos currículos, conteúdos e métodos dos cursos jurídicos em relação ao contexto (social) em que está inserido o fenômeno jurídico. Isso gera uma inquietação, refletida em diversas falas e discursos, tal como o de Santiago Dantas, em famosa aula magistral ainda em 1955.

A Ordem dos Advogados do Brasil, por exemplo, ocupa-se há tempos dessa questão. Em estudos e ações, procura atingir a distribuição da Justiça em seu nascedouro: na formação do operador jurídico. A OAB contribui para a fixação de diretrizes mínimas, fiscaliza cursos jurídicos, atribui selos e ainda realiza exames de aferição de habilidades e conhecimentos. Também alimenta as instituições de ensino superior com estatísticas e dados decorrentes de suas inserções, apontando falhas e virtudes e, sobretudo, indicando caminhos para a gestão acadêmica dos cursos jurídicos.

Não escapa desse cenário a prática jurídica, que, como visto, é preocupação dos cursos jurídicos, ao menos formal, desde sua gênese em território nacional. ${ }^{5}$ Isso revela uma intenção (normativo-teórica, no mínimo) em formar sujeitos com algo mais do que profissionalismo teórico e/ou prática não reflexiva. 
Para que tal intenção se concretize, também é necessário, sem dúvida, um perfil docente adequado, principalmente quando se fala em prática jurídica. Seus professores devem necessariamente exercer o direito, notoriamente a advocacia. Na direção e supervisão das atividades de prática jurídica, admitem-se apenas professores com inscrição ativa na Ordem dos Advogados do Brasil. O professor, para ministrar sua disciplina, além de conhecer o direito material a que ela está vinculado, deve demonstrar conhecimentos elevados de direito processual, assim como de estrutura judiciária. Para além disso, deve transpirar o compromisso que decorre de sua função social, o que o afasta do modelo tradicional das aulas jurídicas (obrigando-o à recomposição de métodos, técnicas e até - por que não? - de suas próprias ideologias).

É nas disciplinas de prática jurídica que o modelo de educação tão combatido por Paulo Freire (centrado no aluno e que vê o professor não mais como o dador e cobrador de conteúdos, mas sim como o tutor e orientador do processo individual de aprendizagem) ganha (ou exige?) espaço. ${ }^{6}$

Além de todo o mencionado, que torna especial o espaço das práticas jurídicas, é imprescindível atentar para os "novos direitos" decorrentes das crises paradigmáticas contemporâneas. Esses desafios quebram a pseudoestabilidade do conhecer jurídico, tornando certa apenas a ideia de sua volatilidade, instabilidade, imprecisão e incompletude. É então que surge mais uma habilidade a desenvolver no graduando (e até no docente, uma vez que formado sob outro paradigma): a criatividade. A prática jurídica (notoriamente o estágio - docência ou curricular obrigatório) é o espaço para resgatar e desenvolver a criatividade jurídica, a problematização do direito e para promover sua reaproximação com a realidade social e com a ética. Vive-se um tempo de esvaziamento do senso crítico, da autonomia intelectual, da reflexão criativa e comprometida com padrões morais mínimos, o que leva à formação de profissionais técnica e humanamente despreparados para a lida com os problemas de uma sociedade complexa, dinâmica e carente. ${ }^{7}$

A prática jurídica deve ser espaço de integração e expansão, de fixação e criação. A prática jurídica deve ser o "choque de vida” necessário ao despertar daquele jurista que honre tal atributo subjetivo e que contribua, com o seu fazer, para a consolidação dos pilares de uma sociedade humana, fraterna, justa.

Para que o espaço da prática jurídica se consolide e as ferramentas se mostrem eficazes, entretanto, é importante desencastelar o conhecimento jurídico (do meio universitário e do meio jurídico tradicional), levando-o ao conhecimento e domínio de seu destinatário: a sociedade. Aqui, toca-se no ponto sensível deste texto: os estágios de docência dos programas de pós-graduação, que deverão passar a preparar docentes também para as atividades práticas.

Algumas instituições de ensino superior já realizam ações comunitárias (palestras, saídas a campo etc.) e participam ativamente dos meios de comunicação social (folhetos explicativos, rádios comunitárias etc.). O Estágio de Prática Jurídica pretende 
aprimorar a relação do direito com outros ramos da ciência, bem como destes todos com a realidade. A visão dos fenômenos sociais a partir de suas múltiplas dimensões é que permite sua perfeita compreensão e o consequente alcance das alternativas para seus eventuais descompassos e problemas. Desempenhar novas e necessárias habilidades é fato inconteste da vida cotidiana do jurista. Por isso, habilidades como a boa leitura da realidade (que parte da perfeita compreensão do social, do político e do econômico), a excelência na comunicação (e na persuasão a partir desse talento) e o compromisso social constituem o diferencial dos egressos que têm o privilégio de serem capacitados para chefs jurídicos, especialmente em uma era em que milhares de profissionais são despejados no mercado de trabalho a cada ano.

De tudo, certezas: os cursos jurídicos não podem mais se contentar apenas em formar pessoas que logrem aprovação no exame da Ordem dos Advogados do Brasil e outros tantos certames. Da mesma forma, e tendo isto como supedâneo, os cursos jurídicos de pós-graduação strictu sensu não podem, em seus estágios de docência, limitar a atuação do estagiário a aplicar trabalhos, fazer controle de frequência e tomar conteúdos, assim centrando sua presença principalmente nas denominadas disciplinas propedêuticas.

Isso seria formar auxiliares de cozinha, jeitosos, mas sem criatividade, raciocínio autônomo ou qualquer compromisso para além de suas panelas (salvo vocacionadas e honrosas exceções). A instituição de ensino superior deve ter como desiderato formar chefs jurídicos: surpreendentes, habilidosos, semeadores de novos paradigmas, lastreados na ciência e na renovação constante de seus saberes e, sobretudo, comprometidos com "as fomes" do mundo.

A prática (onde localizados os estágios) promove o conhecer ao status de viver. Se esse conhecimento for completo, comprometido e complexo (transdisciplinar, por exemplo), a prática, então, passará a ser vida em plenitude.

: ARTIGO APROVADO (16/05/2010) : RECEBIDO EM 01/10/2009

NOTAS

1 Resolução n ${ }^{\circ} 9$ do CNE/CSE, artigo $5^{\circ}$.

2 Resolução n ${ }^{\circ} 9$ do CNE/CSE: “Art. $5^{\circ}$ - O curso de graduação em Direito deverá contemplar, em seu Projeto Pedagógico e em sua Organização Curricular, conteúdos e atividades que atendam aos seguintes eixos interligados de 
formação: [...] III - Eixo de Formação Prática, objetiva a integração entre a prática e os conteúdos teóricos desenvolvidos nos demais eixos, especialmente nas atividades relacionadas com o Estágio Curricular Supervisionado [...]”.

3 Que revogou a Portaria Ministerial $\mathrm{n}^{\circ}$ 1.886, de 30 de dezembro de 1994, bem como todas as demais disposições que lhe sejam contrárias.

4 Talvez esta mácula ainda reste em boa parte dos currículos jurídicos atuais: teoria no início e prática no final. O objetivo ditado pelas novas diretrizes curriculares aponta para a necessária conjugação entre teoria e prática desde os primeiros momentos do curso jurídico.

5 Resolução $\mathrm{n}^{\circ} 9$ do CNE/CSE: “Art. $7^{\circ}$ - O Estágio Supervisionado é componente curricular obrigatório, indispensável à consolidação dos desempenhos profissionais desejados, inerentes ao perfil do formando, devendo cada instituição, por seus colegiados próprios, aprovar o correspondente regulamento, com suas diferentes modalidades de operacionalização. $\S 1^{\circ} \mathrm{O}$ Estágio de que trata este artigo será realizado na própria instituição, através do Núcleo de Prática Jurídica, que deverá estar estruturado e operacionalizado de acordo com regulamentação própria, aprovada pelo conselho competente, podendo, em parte, contemplar convênios com outras entidades ou instituições e escritórios de advocacia; em serviços de assistência judiciária implantados na instituição, nos órgãos do Poder Judiciário, do Ministério Público e da Defensoria Pública ou ainda em departamentos jurídicos oficiais, importando, em qualquer caso, na supervisão das atividades e na elaboração de relatórios que deverão ser encaminhados à Coordenação de Estágio das IES, para avaliação pertinente. $\S 2^{\circ}$ As atividades de estágio poderão ser reprogramadas e reorientadas de acordo com os resultados teórico-práticos gradualmente revelados pelo aluno, na forma definida na regulamentação do Núcleo de Prática Jurídica, até que se possa considerá-lo concluído, resguardando, como padrão de qualidade, os domínios indispensáveis ao exercício das diversas carreiras contempladas pela formação jurídica”.

6 Nesse sentido, ler: FREIRE, Paulo. Pedagogia da autonomia: saberes necessários à prática educativa. São Paulo: Paz e Terra, 2008.

7 Não apenas no sentido econômico do termo, mas no sentido cultural, fraternal, filosófico do mesmo.

\section{REFERÊNCIAS BIBLIOGRÁFICAS}

ADORNO, Sérgio. Os aprendizes do poder. São Paulo: Paz e Terra, 1988.

FINCATO, Denise Pires. La enseñanza jurídica en Brasil y en España: ¿un problema aporético? Tese

(doutorado), Universidad de Burgos, Burgos, 2001. 2 v.

RODRIGUES, Horácio Wanderlei. Novo Currículo Mínimo dos Cursos Jurídicos. São Paulo: Revista dos Tribunais, 1995.

Denise Pires Fincato

Av. Augusto Meyer, 163, cj. 406 Bairro Auxiliadora - 90550-110

Porto Alegre - RS - Brasil dfincatolapucrs.br
PRofESSORA E PESQUISADORA do Programa dE Pós-gRaduaÇão em Direito da PUC do Rio Grande do Sul (PPGD-PuCRS)

MESTRE EM DIREITO PELA UNIVERSIDADE DO VALE DO RIO DOS SINOS (UNISINOS)

DOUTORA EM DIREITO PELA UNIVERSIDADE DE BURgos (ESPANHA)

Advogada 